\title{
Cortical potentials evoked by the onset and the termination of foveal stimulation
}

\author{
NEIL R. BARTLETT, THE UNIVERSITY OF ARIZONA, \\ Tucson, Arizona AND CARROLL T. WHITE,' NAVAL ELEC- \\ TRONICS LABORATORY CENTER, San Diego, California
}

Responses to the termination of brief dim flashes confined to the human fovea are shown to be more pronounced than to the initiation of the flashes. This was true for both red light and for blue.

Studies of human reaction time (for summary, see Pease \& Sticht, 1965) demonstrate that when the stimulus is dim and confined to the fovea, there may be a slightly faster response to the extinction of visual stimuli than to the onset. In the periphery there is, however, a markedly faster response to onsets. It long has been known that there are pronounced off effects in electroretinograms of cone retinae (Granit, 1955). Recently, Efron (1964) has published records showing differences between the average evoked cortical response (ECP) when a flash was terminated and that for the initiation of a flash. Efron made the point that a flash stimulus of finite duration should be considered to consist of no less than two events: the on transient and the off; and he demonstrated rough agreement between the ECP for brief flashes and the synthesis of the ECPs for onset and termination. This report represents another set of records for flash onset and termination, but stimulus arrangements were such as to ensure restriction of the flash to the fovea; furthermore, we have employed flashes of moderate luminance from two wave bands, one at each end of the spectrum. From the suggestion in reaction time data that motor responses under such conditions are faster to flash termination than to initiation, one might expect the ECP for the termination to be more pronounced than that for initiation.

Method. ECPs were obtained from the right occipital lobe of three Ss upon sequential stimulation of the fovea. Four replications, on different days, were made for each S. Recordings were monopolar: the active electrode was located $1 \mathrm{in}$. above the inion and $1 \mathrm{in.}$ to the right of midline, and the reference electrode was on the right ear lobe. Responses were averaged with a Computer of Average Transients (CAT), each average being based on responses to 80 flashes. Further details of recording procedures are given in previous reports (Eason et al, 1964, 1967).

The stimulus was produced by a Sylvania Glow Modulator Lamp R1130B, light from which passed through a Wratten gelatin filter and thence into a flexible optical bundle $0.25 \mathrm{in}$. in diameter protruding into S's observation room. The polished end of the fibers was observed at a distance of 29 in., so the stimulus diameter subtended slightly less than $1 / 2 \mathrm{deg}$. To either side of the stimulus surface there was exposed a minute spot of light produced by an NE51 bulb, operated on dc and masked so that only a small dot of light was visible to $\mathrm{S}$. These two dimly lighted dots, $0.75 \mathrm{in}$. apart, assisted in fixation: $S$ fixated on the position midway between the two dots. The room was light-tight and the fixation dots and the stimulus constituted the only illumination, so prior to observations $S$ was dark adapted. The Glow Modulator was gated by a recycling sequential programmer so as to be on $9.5 \mathrm{sec}$, then off 5.5 , on 8.5 , off 9.5 , on 7.5 , off 6.5 , on 5.5 , off 7.5 , on 6.5 , off 8.5 , and repeat. Thus off time was equal to on. $S$ was instructed to fixate carefully until the stimulus light changed and for at least $1 / 2 \mathrm{sec}$ thereafter; then he might blink or look away for a second or two prior to resuming fixation for the next change. A 3-min rest was given after 40 flashes. When Wratten filter 29 (passing only light above $600 \mathrm{~m} \mu$ ) was used, the Glow Modulator was operated at $18 \mathrm{~mA}$; for filter 49B (passing below $500 \mathrm{m \mu}$ ) the current was $34 \mathrm{~mA}$. Under these conditions, according to the rough measurements we could make with a Macbeth illuminometer and as checked with another technique employing a diffusing screen and a calibrated cadmium sulphide photocell, the luminance of the red flash was approximately $1 \mathrm{ft}-\mathrm{L}$ and the blue $0.1 \mathrm{ft}-\mathrm{L}$.

Results and Discussion. Tracings of the ECPs on each of the four days are exhibited in Fig. I for each $S$ for the two wave bands. It is at once apparent that the ECP for flash termination is more pronounced than that for flash onset, and this held on each day for each S-12 outcomes in a row according to prediction. We

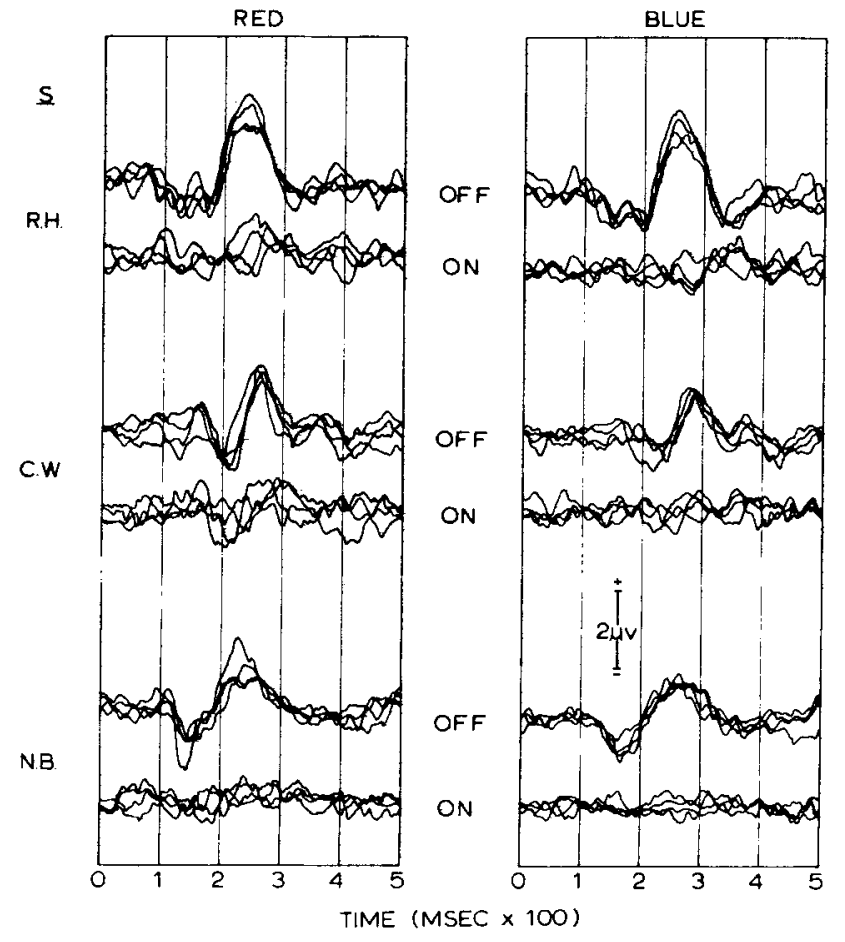

Fig. 1. Averaged evoked occipital responses to initiation ("on") and to termination ("off") of flashes in each of two wave bands. Multiple tracings, each recorded on different days, show degree of consistency in replication.

also made some calculations based on readings for the ordinates of the ECPs. Ordinates for each ECP were read at each successive $10 \mathrm{~ms}$ interval from $100 \mathrm{~ms}$ to 350 , inclusive, and their variance calculated. The result is an index for the wave form related to power. Then for each day's run, the variance for the on ordinates was subtracted from that for off. A conservative $t$ test $(11 \mathrm{df})$ shows the null hypothesis tenable only at a probability far below $1 \%$. For the red flash $t$ was 5.62 , and for the blue, 6.30 .

The marked differences between responses to onsets and to terminations exhibited in these records underscores Efron's admonition that a flash comprises two transients, on and off. But while the greater magnitude of the responses to the off transient is clearly manifest under our conditions, entailing dim foveal flashes with attentive Ss, we are unwilling to extrapolate to any other conditions.

\section{REFERENCES}

PEASE, V. P. \& STICHT, T. G. Reaction time as a function of onset and offset stimulation of the fovea and periphery. Percept. mot. Skills, 1965, 20, 549-554.

EASON, R. G., AIKEN, L. R., WHITE, C. T., \& LICHTENSTEIN, M., Activation and behavior. II Visually evoked cortical potentials in man as indicants of activation level. Percept. mot. Skills, 1964, 19, 875-895.

EASON, R. G., ODEN, D., \& WHITE, C. T., Visually evoked cortical potentials and reaction time in relation to site of retinal stimulation. $E E G$ clin. Neurophysioh, 1967, 22, 313-324.

EFRON, R. Artificial synthesis of evoked potentials to light flash, Ann. N. Y. Acad. Sci., 1964, 112, 292-304.

GRANIT, R. Receptors and sensory perception, New Haven: Yale Univ. Press, 1955, Pp. xii, 369.

\section{NOTE}

1. The authors are grateful to Mr. J. A. Hoke for technical assistance. The opinions and assertions contained herein are the private ones of the writer, and are not to be construed as official, or as reflecting the views of the Navy Department or the naval service at large. 